\title{
3D Geostatistical Modeling and Uncertainty Analysis in a Carbonate Reservoir, SW Iran
}

\author{
Mohammad Reza Kamali, ${ }^{1}$ Azadeh Omidvar, ${ }^{2}$ and Ezatallah Kazemzadeh ${ }^{1}$ \\ ${ }^{1}$ Research Institute of Petroleum Industry (RIPI), West Boulevard, Azadi Sport Complex, Tehran 1485733111, Iran \\ ${ }^{2}$ Department of Geology, Science and Research Branch, Islamic Azad University, End of Ashrafi Esfahani Highway, \\ Simon Boulevard, P.O. Box 1944964814, Tehran, Iran
}

Correspondence should be addressed to Azadeh Omidvar; omidvar.azadeh@yahoo.com

Received 30 March 2012; Revised 8 August 2012; Accepted 24 November 2012

Academic Editor: Agust Gudmundsson

Copyright (c) 2013 M. R. Kamali et al. This is an open access article distributed under the Creative Commons Attribution License, which permits unrestricted use, distribution, and reproduction in any medium, provided the original work is properly cited.

\begin{abstract}
The aim of geostatistical reservoir characterization is to utilize wide variety of data, in different scales and accuracies, to construct reservoir models which are able to represent geological heterogeneities and also quantifying uncertainties by producing numbers of equiprobable models. Since all geostatistical methods used in estimation of reservoir parameters are inaccurate, modeling of "estimation error" in form of uncertainty analysis is very important. In this paper, the definition of Sequential Gaussian Simulation has been reviewed and construction of stochastic models based on it has been discussed. Subsequently ranking and uncertainty quantification of those stochastically populated equiprobable models and sensitivity study of modeled properties have been presented. Consequently, the application of sensitivity analysis on stochastic models of reservoir horizons, petrophysical properties, and stochastic oil-water contacts, also their effect on reserve, clearly shows any alteration in the reservoir geometry has significant effect on the oil in place. The studied reservoir is located at carbonate sequences of Sarvak Formation, Zagros, Iran; it comprises three layers. The first one which is located beneath the cap rock contains the largest portion of the reserve and other layers just hold little oil. Simulations show that average porosity and water saturation of the reservoir is about $20 \%$ and $52 \%$, respectively.
\end{abstract}

\section{Introduction}

The first step in optimizing the use of explored resources is to define the reservoir, which has a determinant role in reservoir management [1]. Definition of a reservoir includes description of empty spaces and size of grains, porosity and permeability of reservoir, identification of facies, sedimentary environment, and description of basin [2].

Three-dimensional models provide the best mechanism for linking all the existing data [3]. Nowadays, efficient threedimensional simulation is popular in all major oil companies and has become an essential part of normal exploration and production activities. To overcome the inherent twodimensional limitation of paper, it is necessary to use defined three-dimensional data. Three-dimensional simulation of geological structures enables collection of all the existing data for a certain project in a united model, by means of which data can be analyzed in software environment [4].

There are several methods for estimation. In a general classification, they can be divided into geostatistical and classical methods. Classical methods are those using classical statistics for estimation, while in geostatistical methods the estimation is made based on spatial structure in the environment [5].

3D geological models play an important role in petroleum engineering. There are different methods for 3D modeling, in each of these methods geological, mathematical, or statistical information is used [6].

Modern specialized software programs can model complicated and nonorderly geological volumes in three dimensions. This is done by using geological maps and construction information for creating a proper model [7]. 
When calculating reserves using any of the above methods, two calculation procedures may be used: deterministic and/or probabilistic. The deterministic method is by far the most common. The procedure is to select a single value for each parameter to input into an appropriate equation and to obtain a single answer. The probabilistic method, on the other hand, is more rigorous and less commonly used. This method utilizes a distribution curve for each parameter, and through the use of Monte Carlo Simulation, a distribution curve for the answer can be developed. Assuming good data, a lot of qualifying information can be derived from the resulting statistical calculations, such as the minimum and maximum values, the mean (average value), the median (middle value), the mode (most likely value), the standard deviation and the percentiles, see Figures 1 and 2.

The probabilistic methods have several inherent problems. They are affected by all input parameters, including the most likely and maximum values for the parameters. In such methods, one cannot back calculate the input parameters associated with reserves. Only the end result is known but not the exact value of any input parameter. On the other hand, deterministic methods calculate reserve values that are more tangible and explainable. In these methods, all input parameters are exactly known; however, they may sometimes ignore the variability and uncertainty in the input data compared to the probabilistic methods which allow the incorporation of more variance in the data.

In recent years, the quantification, understanding, and management of subsurface uncertainties has become increasingly important for oil and gas companies as they strive to optimize reserve portfolios, make better field development decisions, and improve day-to-day technical operations such as well planning. Stochastic approaches based on the standard volumetric equation are now commonly used for screening and value assessment of hydrocarbon assets. Uncertainty in static volumes and recoverable reserves are quantified by Monte Carlo sampling of probability distributions for the controlling parameters in the volumetric equation. Volumes are calculated by simple multiplication of the sampled values for each of the input distributions. As the Monte Carlo sampling and direct multiplication is very fast, 1000s of Monte Carlo loops can be run to provide reliable output distributions.

Although these approaches are very fast, it is often difficult to estimate the intrinsic dependencies between the input parameters, and they provide no quantification or visualization of the spatial location and variability of the uncertainty. An alternative is to use a 3D model as the basis for the volumetric calculations. This allows the dependencies between the various input parameters to be treated in a realistic manner and provides information on the spatial variability of the uncertainty [8]. The main sources of uncertainty come from the reservoir's geological structure, the variability of petrophysical properties, and the OWC and GOC locations $[9,10]$. The probabilistic distribution of Gross Rock Volume (GRV) (MMcu.m) and Stock Tank Oil-in Place (STOIIP) (MMbbls) can then be obtained and used to get unbiased volume estimates and to quantify the risk associated with them $[11,12]$.

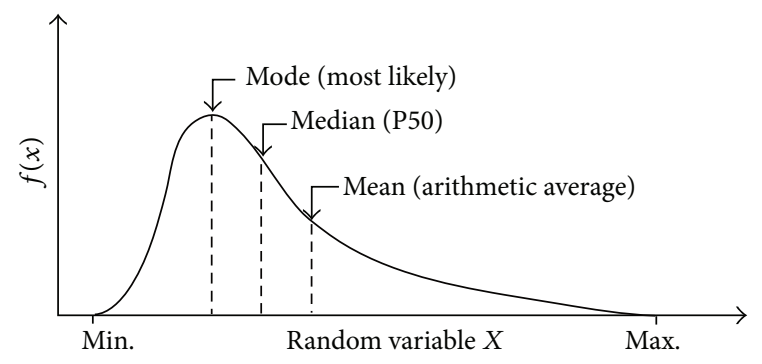

Figure 1: Measures of central tendency.

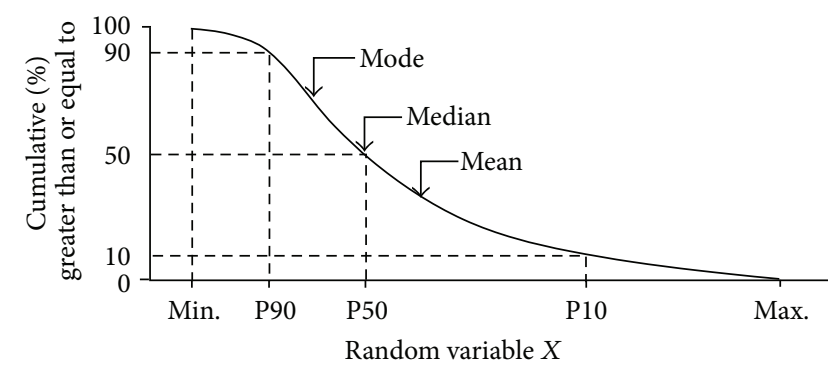

FIgURE 2: Percentiles.

\section{Geological Setting}

The reservoir under study is referred to as Savrak Formation belonging to Zagros petroliferous region. The word "Saravk" is derived from Tange Savrak in the mount Bnatsegna in Khuzestan Province and its type section is located in southwest of the mount Bnagestan.

This Formation is divided into three parts as lower, middle, and upper limestone. Sarvak calcareous Formation in Zagros is usually identified with two shallow and deep facies and spans from Albian to Turonian [13].

\section{Methodology}

This study was carried in two steps. A static model was constructed in the first step and, in order to obtain results with less errors, uncertainty analysis of the resulted model was carried out in the second step.

The existing information for the provision of static model is as follows.

(i) Data obtained from petrophysical logs of 9 wells.

(ii) Well trajectories and underground contour (UGC) map on top of the reservoir.

(iii) Data obtained from core studies and petrographic analyses.

Three-dimensional model generation was performed using the Petrel (Mark of Schlumberger). This software program is able to measure various parameters such as the amount of porosity, fluid permeability, and water saturation 
in each point by using petrophysical data of wells, such as acoustic, nuclear, and electrical logs and by employing positioning and statistical methods [14].

Modeling is carried out in four main steps as follows.

(1) Data loading and data quality controlling (Data input).

(2) Structural modeling.

(3) Creation of three-dimensional petrophysical models for reservoirs properties (property modeling).

(4) Analysis of uncertainty and volumetric calculations.

Briefly, after loading data in the first step and creating a cohesive model proportionate to the existing map, a blocked three-dimensional network was produced (Figure 3). This network as the main body of the model enables the simultaneous study of construction data and petrophysical properties in order to produce reality-oriented models. Moreover, when producing the petrophysical model, it enables petrophysical parameters defined for each well to be generalized to the entire reservoir.

The candidate reservoir is divided into a blocked network in which the properties of each block such as petrophysical and lithological properties are equal in all volumes and similar properties in the blocks which lack information can be estimated in view of distance between networks and the value of data. Obviously, the higher the amount of this information, the more realistic these estimations will be. The dimensions of blocks of this network in line with $X$ and $Y$ have been set 100 * $100 \mathrm{~m}$ and are separated with one-meter distance in reservoir zone and with two meters distance in nonreservoir zones after creation of horizons (Figure 4) and in time of layering. Next, in the step of production of petrophysical models of properties, petrophysical logs information was scaled up.

Scale up means attribution of logs recorded values to blocks of three-dimensional network [15]. Scaled up data are processed during variography step in terms of permanency and normality (average of data is zero and their standard deviation is 1) and related variograms are depicted.

There are several methods to assess normal data distribution. The two most common methods are considered below.

The first method is a graphical approach, so that the cumulative frequency curve of data is plotted according to high-level categories on a paper of which one of the axes is arithmetic scale and the other axis a logarithmic scale. Since the cumulative frequency curve of a normal distribution in terms of high-level categories in these coordinates is a straight line, the closer the extension of the sum of points plotted on this paper to straight line, the closer the data distribution to normal. The second method for evaluating normal distribution of data is the qualitative method. For this purpose, it is sufficient to plot the histogram of data [16].

Variogram analysis is an important part of geostatistical modeling. Indeed, variogram shows the mean square difference between the two values as a function of their increment [17]. The value of variogram is calculated by

$$
\gamma(h)=\frac{\sum_{i=1}^{n_{h}}\left(x_{i}-x_{i+h}\right)^{2}}{2 n_{h}} .
$$

TABLE 1: Parameters of variograms are delineated for porosity and saturation data.

\begin{tabular}{|c|c|c|c|c|c|}
\hline \multicolumn{2}{|c|}{ Nugget Sill } & \multirow{2}{*}{$\begin{array}{c}\text { Effective range } \\
2605.2\end{array}$} & \multirow{2}{*}{$\begin{array}{c}\text { Variogram } \\
\text { spherical }\end{array}$} & \multirow{2}{*}{$\begin{array}{c}\text { layer } \\
\text { Layer } 1\end{array}$} & \multirow[t]{2}{*}{ property } \\
\hline 0.126 & 1 & & & & \\
\hline 0.092 & 1 & 2840.1 & spherical & Layer 2 & Porosity \\
\hline 0.277 & 1 & 3800 & spherical & Layer 3 & \\
\hline 0.290 & 1 & 3529.5 & spherical & Layer 1 & \\
\hline 0.095 & 1 & 4047.8 & spherical & Layer 2 & Water saturation \\
\hline 0.032 & 1 & 3843.2 & spherical & Layer 3 & \\
\hline
\end{tabular}

In the above equation, $\gamma(h)$ is called semivariogram and $2 \gamma(h)$ is called variogram, and $n_{h}$ is the number of pairs of points with the distance $h$ from each other participating in the variogram. $x_{i}$ is a grade in point $i$ and $x_{i+h}$ is grade in a point with distance $h$ from the point $i$.

By calculating variogram for different $h$ values, the $\gamma(h)$ diagram in terms of $h$ can be drawn, and the $h$ value is called lag.

For many modeling, the variogram model begins from a nonzero value and increases up to range called effective range (a), eventually reach to the constant value called sill. The effective range is the range in which the data spatial structure is relevant, and outside the range, the data effect is independent from each other [18] (Table 1).

Property modeling is usually used for inherent properties of a parameter. Variogram is a tool for describing these inherent properties [19]. In other words, variogram is a method of analyzing and describing these spatial changes based on the principle that samples close together are more similar than samples far from each other (Figure 5).

Following this three-dimensional model of reservoir properties including porosity and water saturation are modeled by using output variograms of variography step by sequential Gaussian simulation method (one of probabilityoriented methods) (Figures 6 and 7).

In sequential simulation methods, the places lacking sample are consecutively visited in a stochastic manner until all places without sample are visited. In each place which has no sample, multiple realizations can be obtained from simulated variable on the basis of estimation as well as local uncertainty and in the order that places without sample are visited and the way in which a value in places without sample are simulated. Two sequential simulation methods which are widely used are sequential index simulation (SIS) and sequential Gaussian simulation (SGS).

Sequential Gaussian simulation is the most widely used geostatistical method in the recent modeling projects. This method is very simple and flexible. Sequential simulation of a variable is carried out in five steps: conversion of main data to a new space; variogram modeling in new space; determination of a stochastic route in order to visit all of the places lacking sample; estimation of places without sample in alternate way and finally reversed conversion of simulated values. 


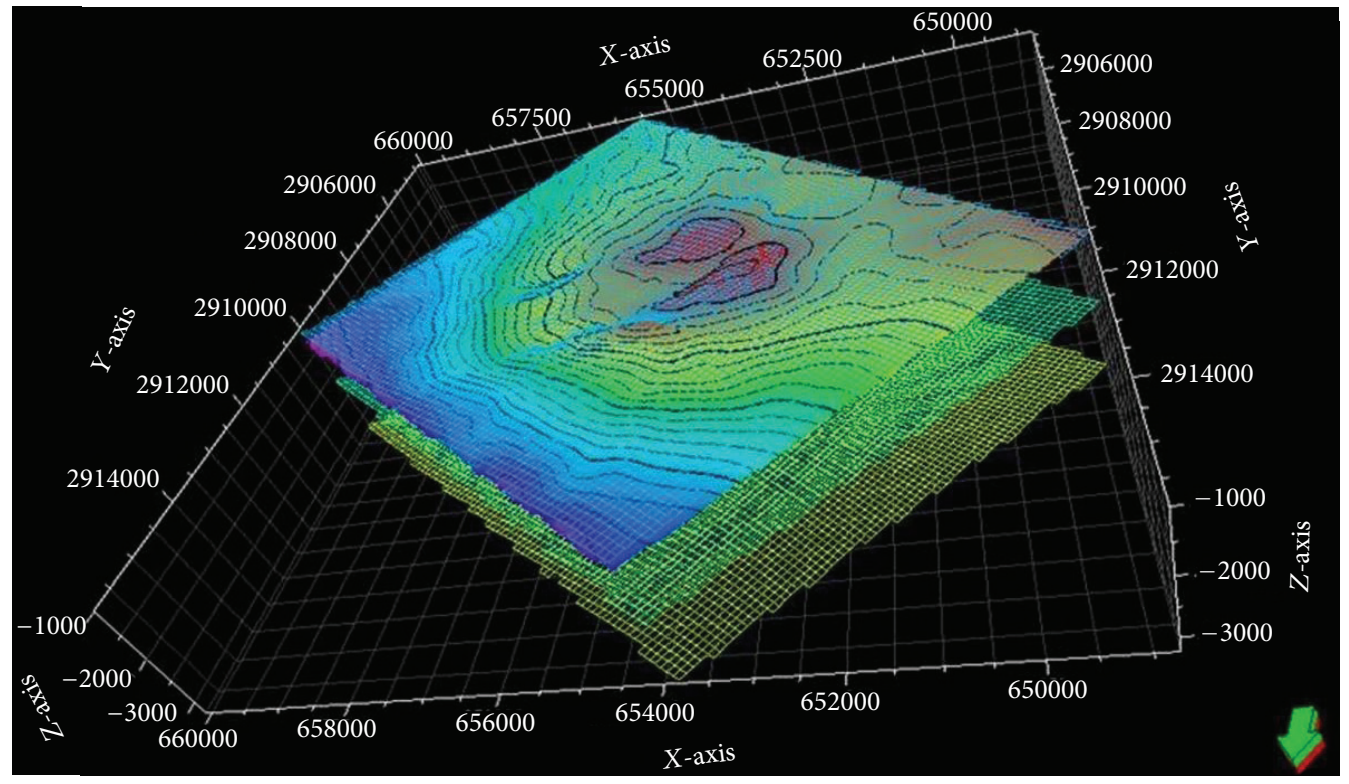

Figure 3: Structural grid of the studied reservoir; dimensions of blocks are $100 \mathrm{~m} * 100 \mathrm{~m} * 1 \mathrm{~m}$ along $X, Y$, and $Z$ directions, respectively.

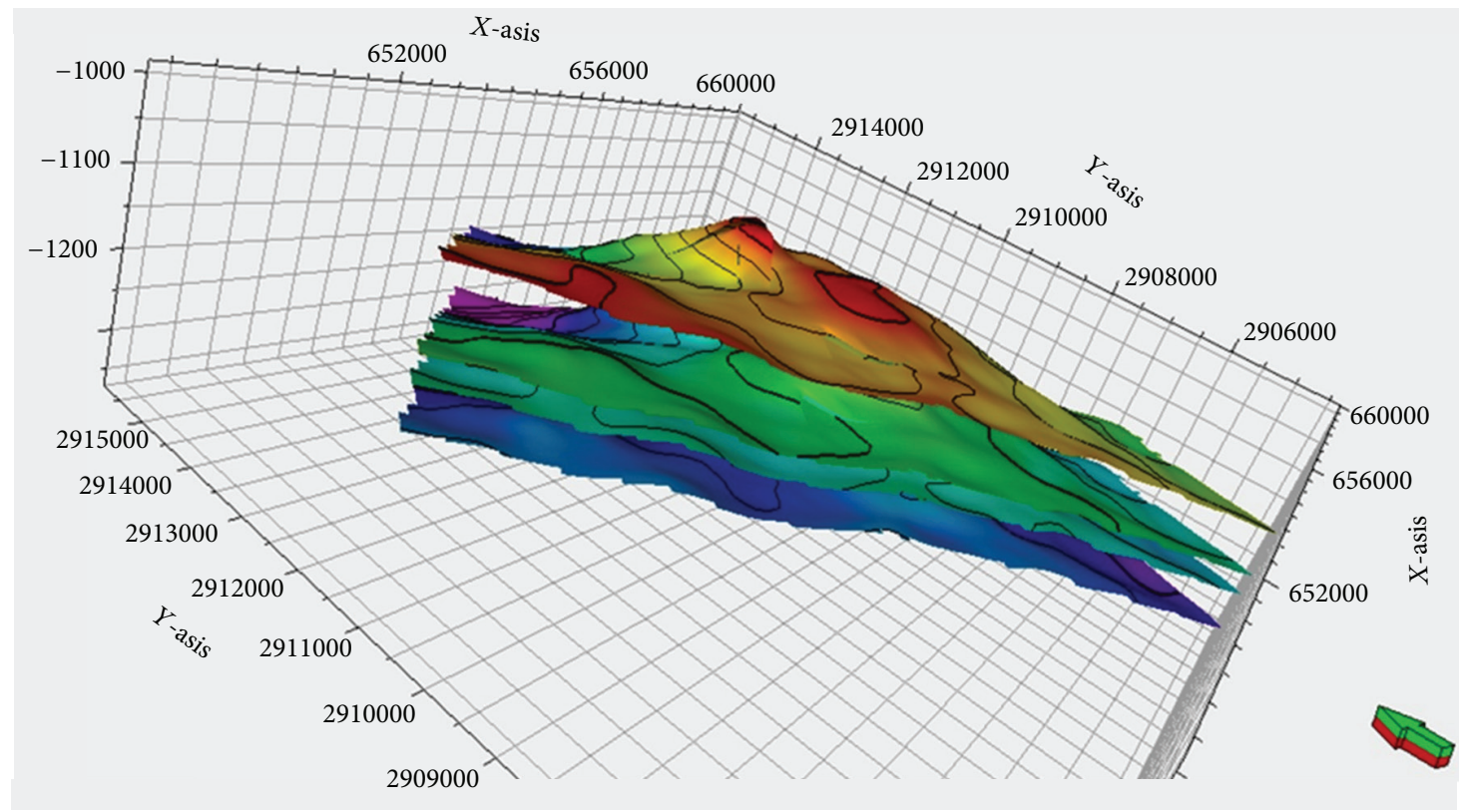

FiguRe 4: Horizons generated in Petrel.

Volumetric calculation produced models are performed on the basis of linear equation. $B_{O}$ and $O W C$ values have been set 1.2 and -1074 in laboratory and field studies.

For oil reservoirs, the original oil-in place (OOIP) volumetric calculation is [20] as follows.

\subsection{Imperial Consider}

OOIP $(\mathrm{STB})=$ Rock Volume $* 7,758 * \phi *(1-S w) * \frac{1}{B_{o}}$ 


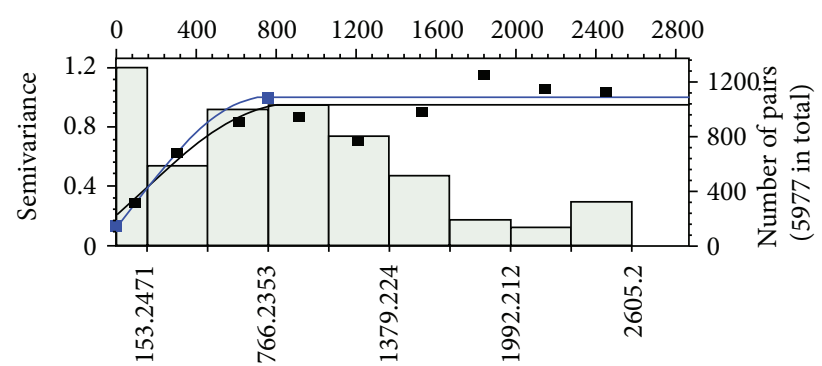

Figure 5: Variogram for porosity data in layer number one. Variogram type is spherical, the sill is 1 , and the nugget is 0.126 .

where rock volume (acre feet) is the $A * h, A$ is the drainage area, acres, $h$ is the net pay thickness, feet 7,758 is the API Bbl per acre-feet (converts acre-feet to stock tank barrels), $\phi$ is the porosity, fraction of rock volume available to store fluids, $S w$ is the volume fraction of porosity filled with interstitial water, $B o$ is the formation volume factor (Reservoir Bbl/STB), $1 / B_{o}$ is the shrinkage $(\mathrm{STB} /$ reservoir $\mathrm{Bbl}), B_{o}$ and $\mathrm{OWC}$ values have been set 1.2 and -1074 in laboratory and field studies.

\section{Uncertainty Analysis}

The available data for oil and gas fields are in general not enough to minimize the uncertainties related to the construction of reservoir models. The understanding of uncertainties involved in reservoir modeling is an essential tool to support decisions in the petroleum industry. The knowledge of uncertainty management related to prediction of hydrocarbon volumes has increased in the last decades, as a result of reliable $3 \mathrm{D}$ geological models made available by improvements in computer processing [21]. Lelliott et al. grouped the sources of uncertainties related to geological modeling into: data density (the density of boreholes used to construct the model); data quality (quality of the data used to construct the model, including borehole elevation, sample type, drilling method, and logging quality); geological complexity (geological variability throughout the site); and modeling software.

According to Zabalza-Mezghani et al. [22], the sources of uncertainties, in reservoir engineering, can be classified as anywhere within the reservoir modeling workflow. Such uncertainties are associated with: the static model, up scaling, fluid flow modeling, production data integration, production scheme development, and economic evaluation. These authors classified the different uncertainty behaviors as deterministic, discrete, and stochastic uncertainties [23].

So, the uncertainties inherent to each input data set used to build 3D static reservoir models cannot be expressed in a single deterministic realization. Each of the said calculations has an inherent uncertainty which causes a major uncertainty in reservoir estimation in time of combination. Threedimensional models also follow this rule and the existence of big elements of uncertainty in modeling steps is undeniable. This amount of error is usually determined by using volumetric equations, but recent software advancements have enabled

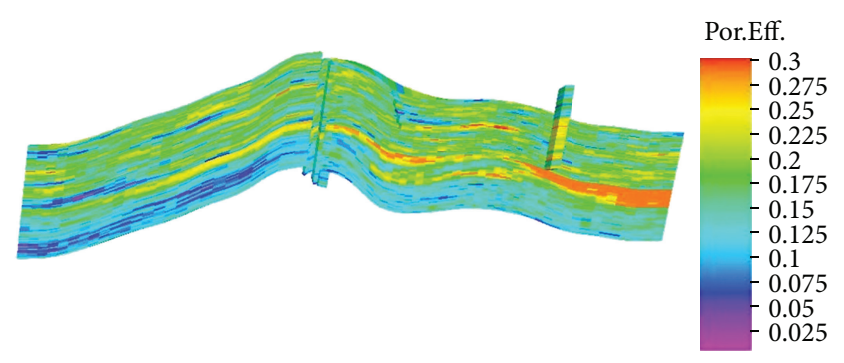

FIGURE 6: Cross-section of porosity distribution which is modeled using SGS algorithm. Note, align along I-Direction.

the use of three-dimensional models as the foundation of investigating this uncertainty in reservoir.

The use of these three-dimensional models has many advantages over estimation based on direct application of volumetric equations. Among these advantages is that threedimensional models enable presentation of inherent correlations in a realistic attitude and this results in more accuracy in our estimation of uncertainty and creation of a better foundation for conscious capital management. In a general classification, we can mention analysis of uncertainty of reservoirs impure stone volume, uncertainty of properties of stone and fluid, and uncertainty of simulations of flow in reservoir.

In the present static model, analysis of uncertainty is performed on reservoir stone volume and consequently volumetric calculations (which is affected by the said parameter). To this end, such parameters as reservoir geometric structure (existing horizons and zones), depth of water and oil (OWC), and three-dimensional models produced for porosity and water saturation have been studied. Each of these factors is separately studied and the amount of its effect on volumetric calculation and the amount of oil is determined. For this purpose, cycles are created in which a combination of realizations is created in each investigation by Mont Carlo method and the effect of factor changes on the result of volumetric calculations are measured. Next, the best choice (closest sample to level of 50\%) and its seed number are identified from among hundreds of produced samples. The results can be shown in histograms (Figures 8, 9, and 10) in which probability level of $10 \%$, probability level of $50 \%$ (reality-oriented model), and probability level of $90 \%$ have been identified and CDF curve can be depicted. This way we can study performance of that parameter on the amount of oil.

In analysis of uncertainty, 300 realizations (normally between 50 and 500) for each of parameters under study were produced by Mont Carlo method and the best routes for creation of petrophysical models of reservoir were determined. The realization made by these routes is selected as optimal model and the results of volumetric calculation are reported as estimations with highest probability and lowest error. Finally, after studying the results of threedimensional simulation of well data, modeling distribution of petrophysical properties and analyzing uncertainty in the present model, the depth of water and oil contact surface 


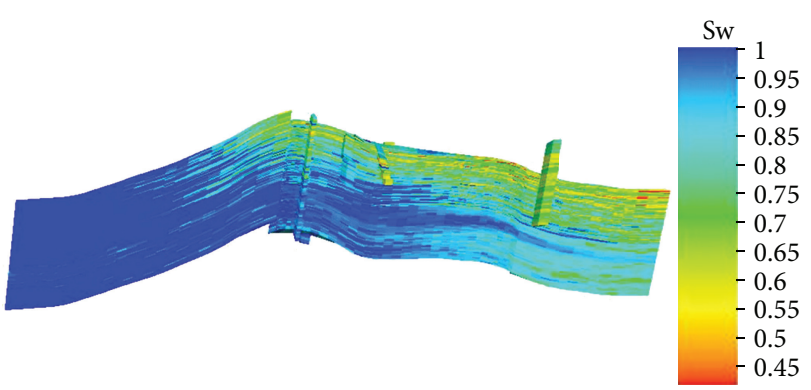

FIGURE 7: Cross-section of water saturation distribution which is modeled using SGS algorithm. Note, align along I-Direction.

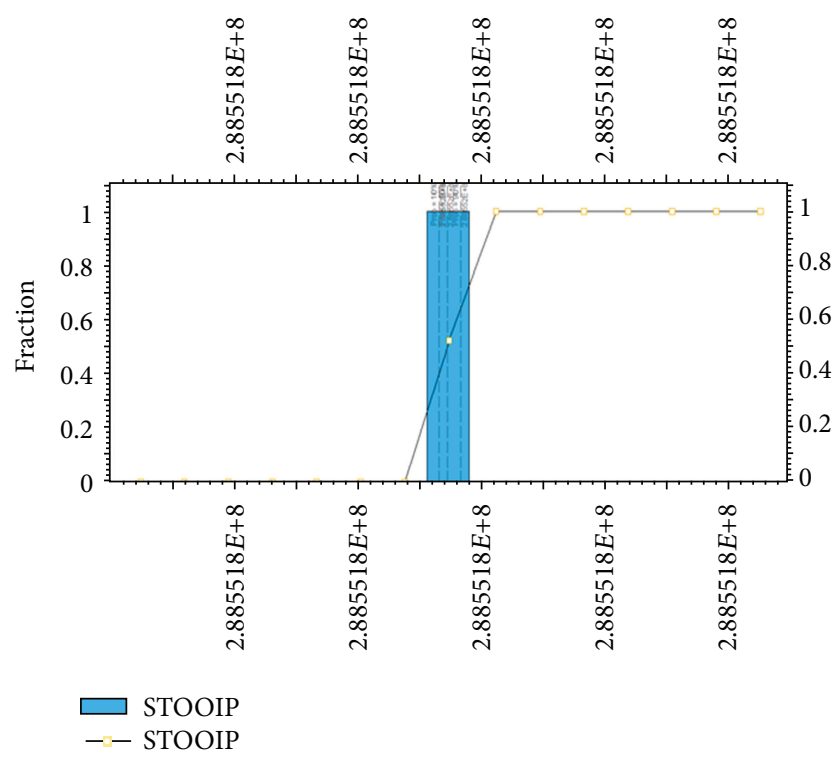

FIGURE 8: Uncertainty analysis, which has performed on reservoir geometry using Monte Carlo method. The figure shows effect of reservoir geometry on calculated STOOIP.

was determined as the most effective factor in creation of uncertainty in the model, meaning that lowest changes in this value have high effect on the amount of estimations because the depth has a direct effect on the volume of reservoir stone (geometrical structure of reservoir) and finally on the amount of estimation of reserve amount. It is evident that in order to minimize this error (uncertainty), the certainty of this value must be increased. To this end, accurate recording of this depth in more wells and more situations in the reservoir can give us a more reliable value (a more frequent value).

\section{Conclusion}

The results of geostatistical simulation and creation of threedimensional models from petrophysical parameters and analyses of uncertainty in reservoir indicated the following.

(i) Sequential Gaussian simulation is very efficient in determination and investigation of uncertainties of three-dimensional models owing to their high accuracy, absence of softening property and possibility to

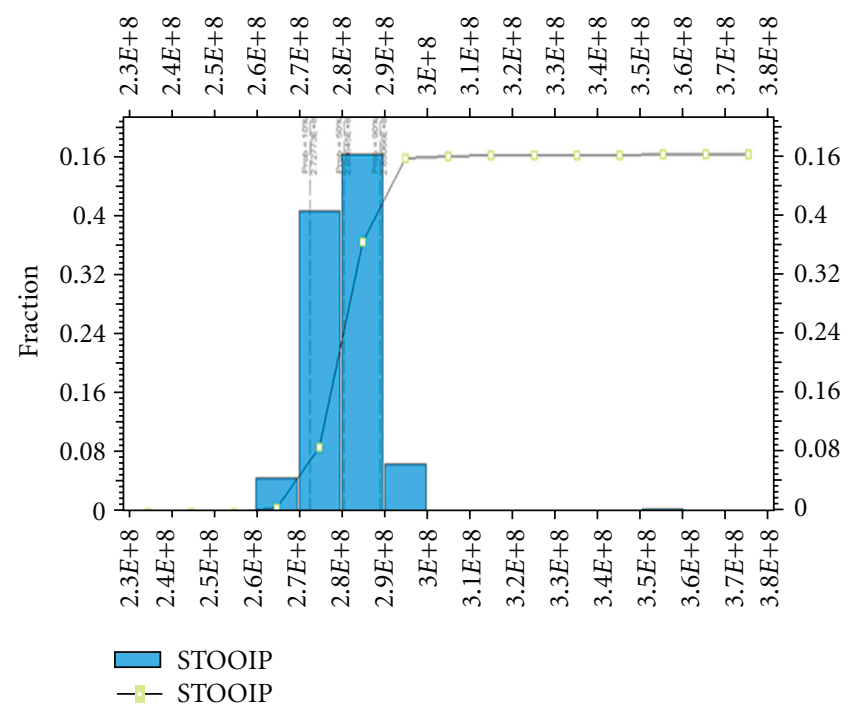

FIGURE 9: Uncertainty analysis, which has performed on reservoir geometry using Monte Carlo method. The figure shows effect of OWC on calculated STOOIP.

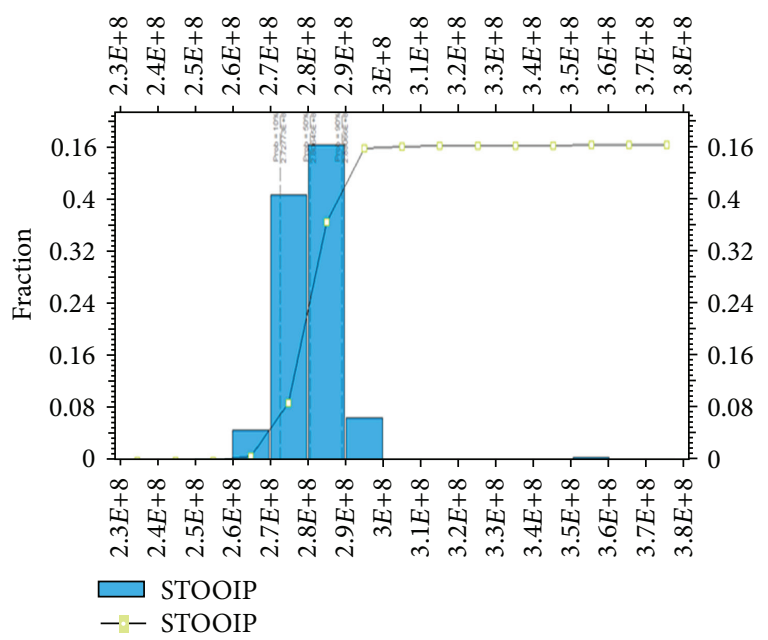

FIGURE 10: Uncertainty analysis, which has performed on reservoir geometry using Monte Carlo method. The figure shows effect of property distribution on calculated STOOIP.

create many three dimensional realizations in which heterogeneity and scope of changes in variables are shown well.

(ii) According to results of study of uncertainty, the depth of water and oil contact surface was determined as the most effective parameter in calculations. Therefore, it is obvious that special care must be taken in determination and investigation of changes of this surface in reservoir. These changes have direct effect on geometry and total volume of reservoir (bulk volume) and finally on the amount of reserves.

(iii) The results of simulation showed that layer no. 1 holds the highest volume of oil and has constituted oil zone of the reservoir under study. 
(iv) Generally in the simulations performed, the average porosity of reservoir was about $20 \%$ and water saturation $52 \%$.

(v) In volumetric calculations, amount of reserves in the major layer (layer 1) is estimated 280 million barrels.

\section{References}

[1] M. Nikravesh, "Computational intelligence for geosciences and oil exploration," in Forging New Frontiers: Fuzzy Pioneers I, vol. 66, pp. 267-332, California University Press, 2007.

[2] B. Yeten and F. Gümrah, "The use of fractal geostatistics and artificial neural networks for carbonate reservoir characterization," Transport in Porous Media, vol. 41, no. 2, pp. 173-195, 2000.

[3] G. Zamora Valcarce, T. Zapata, A. Ansa, and G. Selva, “Threedimensional structural modeling and its application for development of the El Portón field, Argentina," AAPG Bulletin, vol. 90, no. 3, pp. 307-319, 2006.

[4] R. R. Jones, K. J. W. McCaffrey, P. Clegg et al., "Integration of regional to outcrop digital data: $3 \mathrm{D}$ visualisation of multi-scale geological models," Computers and Geosciences, vol. 35, no. 1, pp. 4-18, 2009.

[5] R. Haining, Spatial Data Analysis: Theory and Practice, Cambrige University Press, Cambrige, UK, 2003.

[6] J. W. Jennings Jr., F. J. Lucia, S. C. Ruppel, A. John, and G. Katherine, "3D modeling of startigraphically controlled petrophysical variability in the South Wasson Clear Fork reservoir," in Proceedings of the SPE Annual Technical Conference and Exhibition, pp. 2209-2223, San Antonio, Tex, USA, October 2002.

[7] O. Kaufmann and T. Martin, "3D geological modeling from boreholes, cross section and geological maps, application over former natural gas storages in coal mines," Computers and Geosciences, vol. 34, pp. 278-290, 2008.

[8] A. MacDonald and J. L. Tollesfrud, "3D reservoir Uncertainty modeling workflows, production and benefits," Roxar, September 2008.

[9] D. P. Hampson, J. S. Schuelke, and J. A. Quirein, "Use of multiattribute transforms to predict log properties from seismic data," Geophysics, vol. 66, no. 1, pp. 220-236, 2001.

[10] P. J. Hatchell, "Fault whispers: transmission distortions on prestack seismic reflection data," Geophysics, vol. 65, no. 2, pp. 377-389, 2000.

[11] K. Hirsche, J. Porter-Hirsche, L. Mewhort, and R. Davis, "The use and abuse of geostatistics," Leading Edge, vol. 16, no. 3, pp. 253-260, 1997.

[12] M. T. Olowokere, "Geostatistical modeling of interval velocity to quantifying hydrocarbon resource in multi-layer reservoir from TMB field, Niger delta," International Journal of Physical Sciences, vol. 5, no. 12, pp. 1897-1907, 2010.

[13] H. Motii, "Geology of Iran, Zagros Geology," Geological Survey of Iran, 2009.

[14] Schlumberger, "Petrel Introduction Course," Seismic-toSimulation Software petrel introduction course, 2008.

[15] Schlumberger, "Petrel Introduction Course," Shlumberger information solutions, 2006.

[16] M. Abdideh and D. Bargahi, "Designing a 3D model for prediction the top of formation in oil fields using geostatistical methods," Geocarto International Journal, vol. 27, pp. 569-579, 2012.
[17] N. Cressie and D. M. Hawkins, "Robust estimation of the variogram," Journal of the International Association for Mathematical Geology, vol. 12, no. 2, pp. 115-125, 1980.

[18] R. Corstanje, S. Grunwald, and R. M. Lark, "Inferences from fluctuations in the local variogram about the assumption of stationarity in the variance," Geoderma, vol. 143, no. 1-2, pp. 123-132, 2008.

[19] Schlumberger, "Property Modeling Course," Shlumberger information solutions, 2004.

[20] L. Dean, "Reservoir engineering for geologists," Part 3-Volumetric Estimation, Reservoir no. 11, pp. 21-23, 2007.

[21] M. R. Lelliott, M. R. Cave, and G. P. Walthall, "A structured approach to the measurement of uncertainty in 3D geological models," Quarterly Journal of Engineering Geology and Hydrogeology, vol. 42, no. 1, pp. 95-105, 2009.

[22] I. Zabalza-Mezghani, E. Manceau, M. Feraille, and A. Jourdan, "Uncertainty management: from geological scenarios to production scheme optimization," Journal of Petroleum Science and Engineering, vol. 44, no. 1-2, pp. 11-25, 2004.

[23] J. F. Bueno, R. D. Drummond, A. C. Vidal, and S. S. Sancevero, "Constraining uncertainty in volumetric estimation: a case study from Namorado Field, Brazil," Journal of Petroleum Science and Engineering, vol. 77, no. 2, pp. 200-208, 2011. 

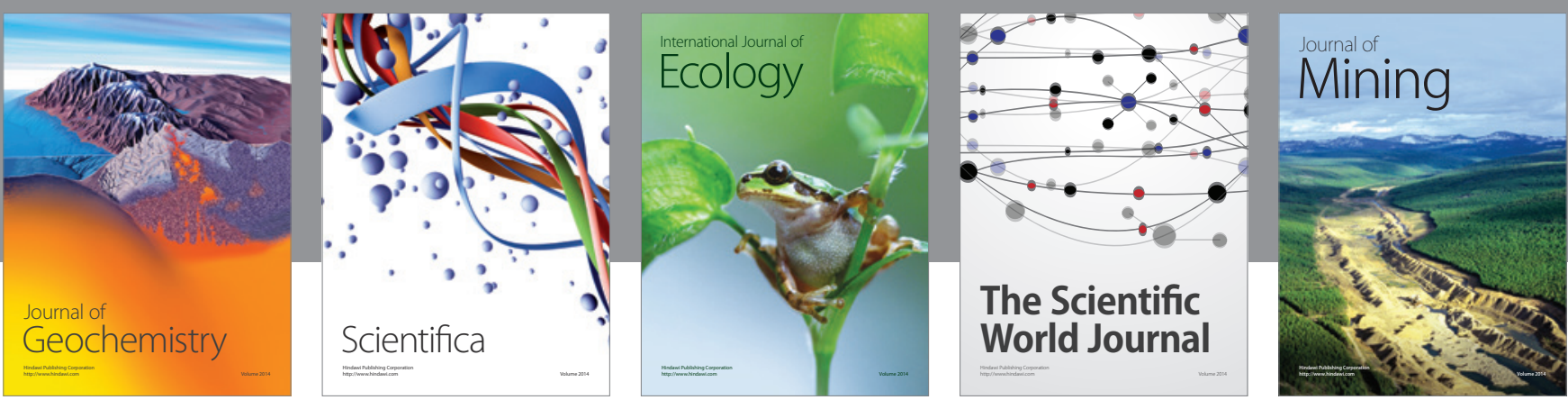

The Scientific World Journal
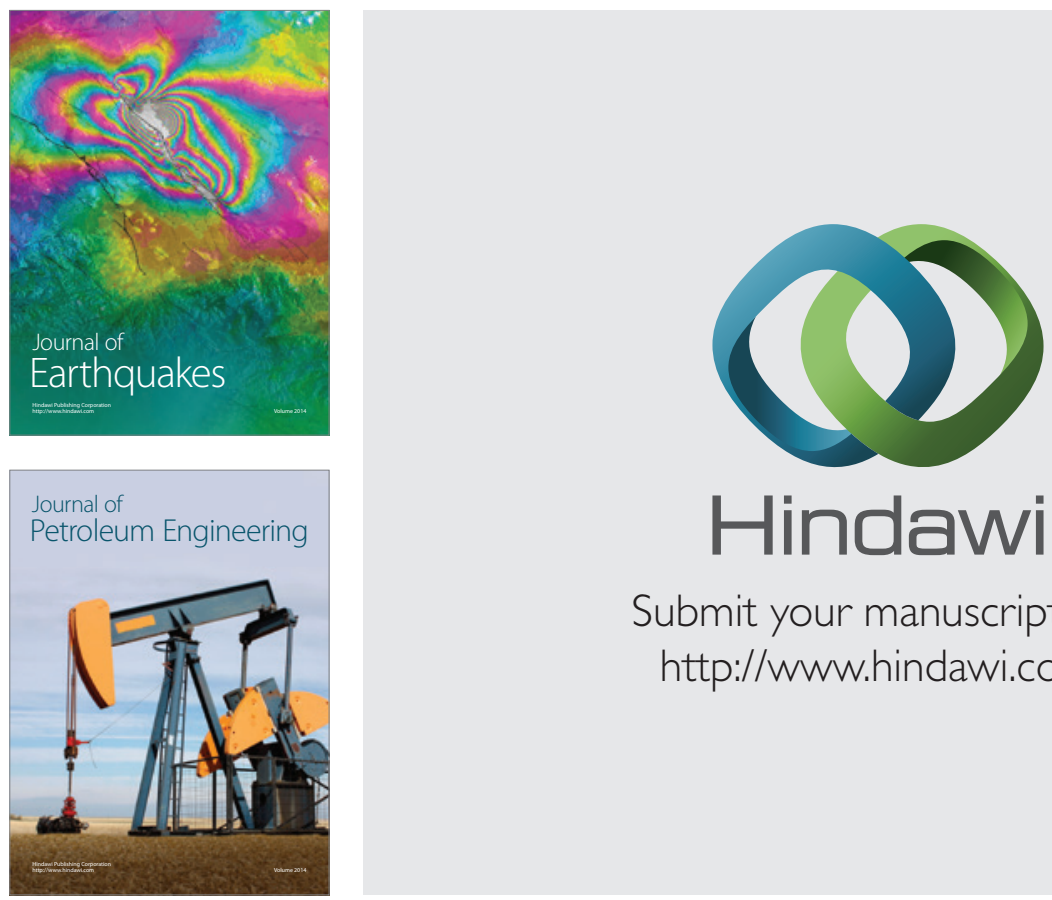

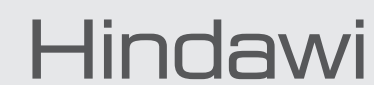

Submit your manuscripts at

http://www.hindawi.com
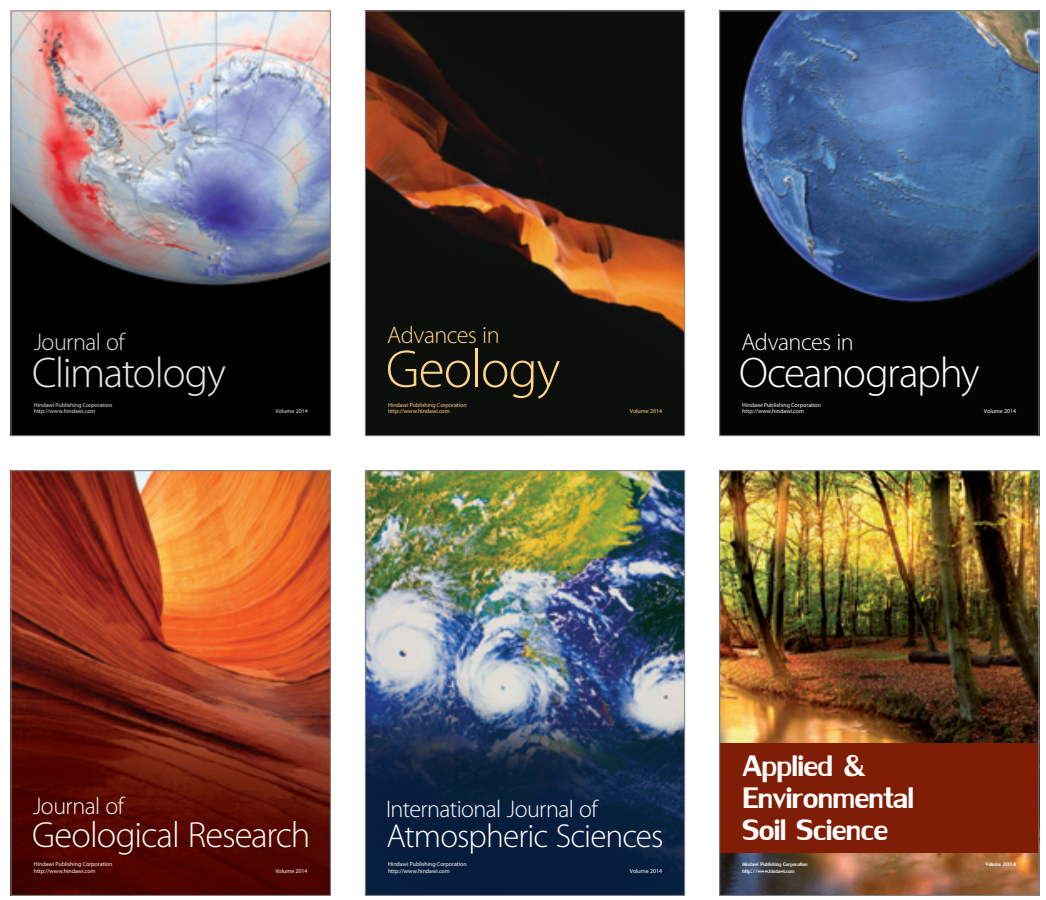
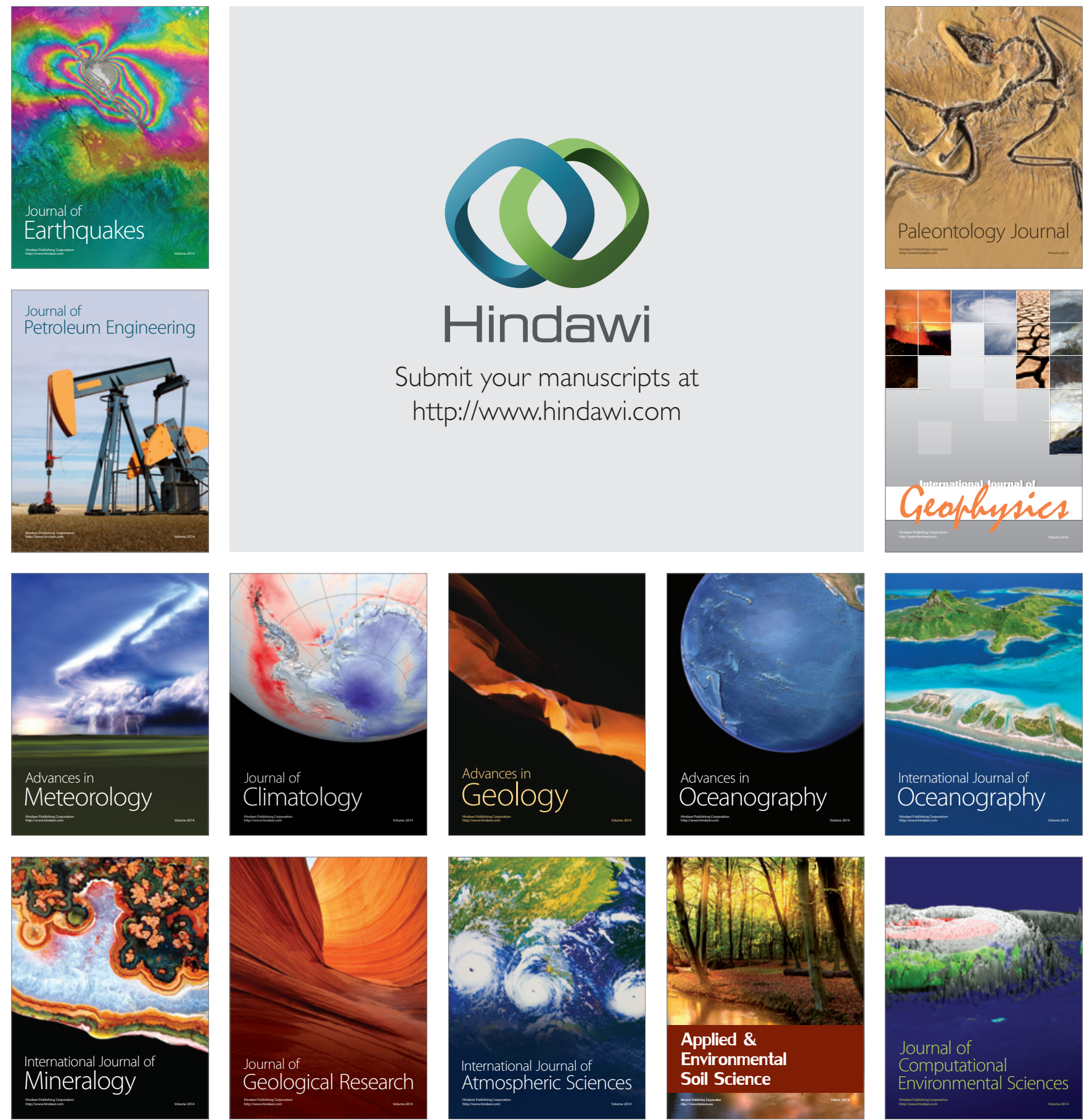